\title{
The gospel of contingency
}

Christian de Duve

Full House: The Spread of Excellence from Plato to Darwin. By Stephen Jay Gould. Harmony/Cape. Pp. 244. \$25, £16.99. UK title is "Life's Grandeur".

WHAT is the difference between a drunkard who, staggering out of a pub, ends in the gutter, and life, which, starting from primitive bacteria, eventually came to compose the "Well-tempered Clavier", paint the Sistine Chapel ceiling and discover natural selection? None, according to the distinguished palaeontologist and popular science writer Stephen Jay Gould. In both cases, random movement devoid of directional bias becomes cumulatively slanted in one direction - either the gutter or humankind - for the simple reason that any excursion in the other direction bumps into a wall either the pub's wall or the limit of minimal complexity compatible with life. Only one direction is open and, because of the laws of probability, is invaded ever farther, given enough time.

Other 'case studies' are brought up in support of the book's main theme - consider the 'full house', not just a small part of it. These include Gould's own successful bout with mesothelioma, a moving story, told with commendable restraint, of the author's finding strength - fortunately helped by an effective drug - in his discovery that the survival distribution curve of patients afflicted with the disease has an extended right tail; the evolution of the horse, a false paradigm of directionality merely expressing the failure of all other
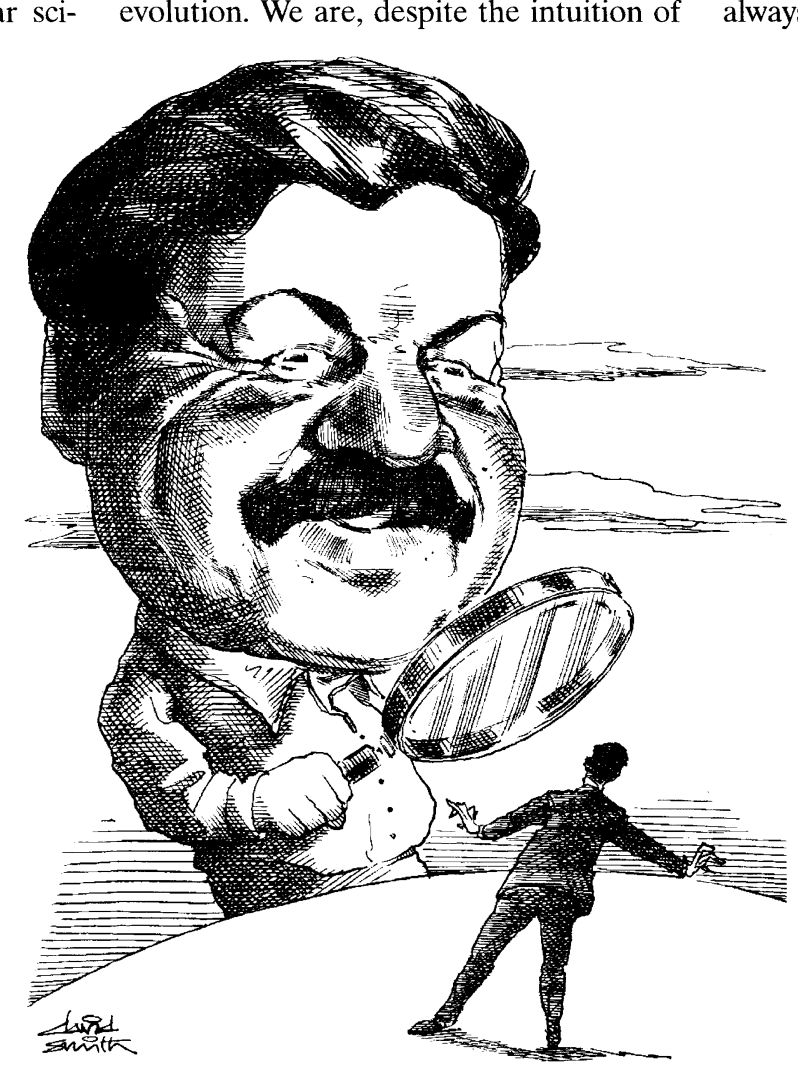

our misguided hubris, no more than a tiny tail ridiculously trying to wag a large dog. If you believe otherwise, try living in boiling water, in the Arctic Ocean, in drying brine or inside deeply buried rocks.

To those familiar with Gould's ideas, this message will come as no news. What will surprise is the tone of the book, which is very different from the author's elegantly written columns in Natural History, the monthly magazine of the New York Museum of Natural History, and from such masterly displays of lucid, scholarly erudition as his Ontogeny and Phylogeny (Harvard University Press, 1977). Abandoning sober intellectual discourse and relying instead on parables and assertions to spread the gospel of contingency, Gould here presents his ideological views in characteristic evangelical style, admonishing all of us sinners to mend our ways and see the light, as he himself has done before us, vituperating against all those who persist in their errors and fail to recognize the truth.

Indeed, much of the book is devoted to denouncing common errors and fallacies, nouns that, together with such variations as delusion, mistake, misconception, misconstruction, misreading, misunderstanding, prejudice, bias, distortion, wrongness and myopic vision, and the corresponding adjectives, occur some 150 times - I made a rough count - throughout the work, with, as counterweight, the author's own "insight", his "eureka" that "humans can occupy no preferred status as a pinnacle or culmination", his discovery that "life has always been dominated by the bacterial mode" and always will be.

For that is the pernicious heresy that needs to be uprooted, the arrogantly anthropocentric belief that the emergence of humankind and, more generally, of consciousness and intelligence, reflects some kind of directionality in biological evolution. The many subtle ways in which this concept of directionality can be dissected and the searching analyses to which it may be, and has been, subjected in the light of modern knowledge are all disregarded in favour of the sophist's strategy of building a straw man, in which complexity, an objective reality that the author recognizes, albeit reluctantly, is insidiously converted into the subjective notion of progress. This notion is then attacked in a manner more suited to the end of the nineteenth century - the author's favourite - than to that of the twentieth. Indeed, except for a few references to some recently discovered bacteria, Gould ignores all the late developments in genetics, biochemistry, cell biology and molecular biology, keeping strictly to his own turf of descriptive palaeontology and choosing astonishingly trivial examples to support his message. Nowhere is a case of true evolutionary increase in complexity addressed in any serious fashion. Nowhere are the molecular mechanisms and constraints of Darwinian evolution mentioned, let alone taken into account.

The book is clearly aimed at a new target for Gould: a readership that needs to be told that living organisms do not disobey the second law of thermodynamics and why; that has yet to be introduced to elementary notions of probability and to the shapes of statistical distribution curves; that must be taught the difference between a mean, a median and a mode, and shown the lack of significance of a mean without its variance; that is more interested in baseball than in evolution, but can be lured by according to some shaky calculations, the 
love of the former to take an interest in the latter and so become converted to Gould's creed of contingency. If you don't recognize yourself in this description, don't read the book, especially if you are a Gould aficionado. It will only make you sad.

Christian de Duve, emeritus professor at the University of Louvain, Belgium, and at the Rockefeller University, New York, is at the International Institute of Cellular and Molecular Pathology, 75 Avenue Hippocrate, B-1200 Brussels, Belgium. His most recent book, Vital Dust: Life as a Cosmic Imperative, is now out in paperback. BasicBooks, $\$ 14$.

\section{Why God plays dice}

\section{David Mermin}

Beyond Science. By John Polkinghorne. Cambridge University Press: 1996. Pp. 131. £13.95, \$19.95.

All those with even a modicum of intelligence who believe that 'creation science' should be given equal time with evolution in school curricula ought to read this charming little book. John Polkinghorne makes a case that, far from being at odds with the existence of a creator, the fact that evolution is possible at all is powerful evidence of underlying design at another level.

A prominent role in the argument is played by the constellation of ideas associated with the various anthropic principles. Evolution points to God as the Great Tuner of fundamental constants. Polkinghorne finds this far more compelling than the notion that our Universe appears delicately adjusted to make the evolution of life possible, because if it weren't we wouldn't be here to notice it. And he is sceptical of the view that, if the stability of atomic nuclei were grossly altered by tiny changes in certain coupling constants, different avenues would open up to the development of complex carriers of intelligence, which we simply lack the wisdom to imagine.

In addition to the miraculous values of the fundamental constants, there is also evidence of design in the wonderful "opportunity for the interplay of chance and necessity" afforded by quantum theory, which seems ingeniously contrived to be both flexible enough to allow evolutionary variation, yet not so floppy as to threaten the persistence of successful new life forms.

Polkinghorne's grand extension of the argument from design shifts the grounds for scepticism from Darwin back to Hume, about whom he has only a little to say. The problem of evil, he remarks, "can at least be addressed by the insight that this is the necessary cost of a universe allowed to make itself, whose shuffling explorations of possibility will have to have ragged edges". The question of who tuned the Tuner does not come up.

Yet another facet of his case is provided by the mystery of consciousness: why should natural selection have given rise to self-awareness? Would not mindless automata have been at least as successful? The views of many philosophers, here and elsewhere, receive some welldeserved jabs. (On exploring the nature of consciousness by way of thought experiments with extraordinary duplicating machines: "Well, philosophy is wonderful, but peculiar premises may lead to peculiar conclusions.") So do computer models of the mind, for computers are useless without a program. In Polkinghorne's view of consciousness, God appears to be the Prime Programmer Unprogrammed.

Only apparently unrelated to these religious concerns is a critical examination, early in the book, of the account of science as a social construction. This contribution to the 'science wars', unusually temperate for a scientist, lucidly states the claims and articulates the naiveties of the so-called 'strong programme' in the sociology of scientific knowledge. Polkinghorne can be poetic in his defence of objective reality: "Far from the physical world proving to be like clay in our theoretical hands, it displays a diamond-like hardness, resistant to our expectations and imposing upon our minds its idiosyncratic and unanticipated structure." Scientists who admire this elegant dismantling of the view that their discipline lacks objective content may be startled to find later in the book the same thoughtful approach applied to the view that moral and aesthetic principles are social constructions. I suspect the defence of the objectivity of scientific knowledge may have been cunningly contrived to set us up for his attack on cultural relativism.

I have two major criticisms. Polkinghorne takes our ability to treat nature at the quantum level as evidence that our capabilities go well beyond anything evolution could have given rise to, for nothing in the struggle for survival could have required us to be creatures capable of such an understanding. I would have put it just the opposite way. It is because nothing required us to apprehend atomic structure during our evolutionary development that we are incapable of understanding what it is that quantum physics describes. Quantum mechanics is weird to us because we can make inferences about the atomic world only indirectly through the correlations we can arrange for it (called measurements) with those parts of the world (called classical) that evolution has outfitted us directly to apprehend. Polkinghorne dismisses too lightly the mysterious character of quantum mechanics. Although I think I know what he has in mind when he says "[y]ou could never build a wave out of finite collections of particles, but a wave-like state is one with an indefinite number of particles making it up", I would not agree that this explains "how the trick is done" in electron diffraction.

And an eloquent discussion of how it may all end - decay into low-grade radiation, fiery Big Crunch or the persistence of ever-adapting forms of life to the very end - comes down from these lofty heights with a resounding thud for the non-Christian reader with a final slightly uncomfortable ("candour requires me to add") declaration of faith in the resurrection of Jesus Christ. Provincial Christian mythology is a blemish on so grand a theological vision.

I nevertheless enjoyed the book immensely. Although I believe this latetwentieth-century version of the argument by design carries many of the flaws of its venerable predecessors, Polkinghorne's literate sense of wonder at the magical richness of things shines out on almost every page, whether or not one agrees that it implies a creator.

David Mermin is in the Department of Physics, Cornell University, Clark Hall, Ithaca, New York 14853-2501, USA.

\section{From the top down}

\section{Philip W. Anderson}

How Nature Works: The Science of SelfOrganized Criticality. By Per Bak. Copernicus/Springer: 1996. Pp. 205. \$27, $£ 20.50$.

THE rarefied air of the Santa Fe Institute in New Mexico seems to encourage the universalist persuasion: to each scientist, his great idea really seems to be the "theory of everything" that has escaped previous notice, and supersedes all of those promulgated by previous Santa Fe sages (and others). Per Bak now tries to persuade us that he has uniquely found out "how nature works".

His particular version of the theory of everything is 'self-organized criticality', a theory and a generic scenario of which I have long been a public advocate. It leads, in my mind correctly, to sobering and counterintuitive conclusions about a wide variety of natural and social processes such as climate, tectonics and the macroeconomy. I therefore consider this book a 'must read', despite its exaggerated claims and obvious weaknesses, but because of its importance I could wish that it had been written with more care.

First, let me give a rough idea of Bak's 